\title{
The Effective Use of Straw Crops as Feedstock for the Complex Processing into Biofuel
}

\author{
Anatoliy P. Burdukova, \\ Oleg I. Lomovsky ${ }^{\mathrm{b}}$, Aleksey L. Bychkov ${ }^{\mathrm{b}}$, \\ Mikhail Yu. Chernetskiy ${ }^{\mathrm{a}, \mathrm{c}}$ and Galina V. Chernova*a \\ ${ }^{a}$ S.S. Kutateladze Institute of Thermophysics SB RAS \\ 1 Academician Lavrentyev, Novosibirsk, 630090, Russia \\ ${ }^{b}$ Institute of Solid State Chemistry and Mechanochemistry SB RAS \\ 18 Kutateladze Str., Novosibirsk, 630128, Russia \\ 'Siberian Federal University \\ 79 Svobodny, Krasnoyarsk, 660041, Russia
}

The article presents a new strategy for processing lignocellulosic feedstock - straw crops. Recycling is based on the organization of biotechnological production that uses carbohydrates for bioethanol production, as well as processing waste with a high content of lignin in high-energy solid fuel. The results of theoretical and experimental studies on combustion of the particulate fuel with a high content of lignin are presented. Proposed new technological solutions for the creation of highly efficient and environmentally friendly energy average power plants. These energy sources will enable the process of energy processing of carbohydrates into bioethanol, and in case of excess energy -for energy to outside customers.

Keywords: biomass, biofuels, mechanical activation, microgrinding, modeling of combustion processes.

Citation: Burdukov A.P., Lomovsky O.I., Bychkov A.L., Chernetskiy M.Yu., Chernova G.V. The effective use of straw crops as feedstock for the complex processing into biofuel, J. Sib. Fed. Univ. Eng. technol., 2018, 11(2), 229-241. DOI: 10.17516/1999494X-0026.

(C) Siberian Federal University. All rights reserved

* Corresponding author E-mail address: chernova@itp.nsc.ru 


\title{
Эффективное использование соломы
}

\section{зерновых культур в качестве сырья \\ для комплексной переработки в биотопливо}

\author{
А.П. Бурдуков ${ }^{\mathrm{a}}$ О.И. Ломовский ${ }^{\sigma}$, \\ А.Л. Бычков ${ }^{\sigma}$, М.Ю. Чернецкий ${ }^{a, \mathrm{~B}}$, Г.В. Чернова ${ }^{\mathrm{a}}$ \\ ${ }^{a}$ Институт теплофизики им. С.С. Кутателадзе СО РАН \\ Россия, 630090, Новосибирск, пр. Академика Лаврентьева, 1 \\ ${ }^{6}$ Институт химии твердого тела и механохимии СО РАН \\ Россия, 630128, Новосибирск, ул. Кутателадзе, 18 \\ ${ }^{6}$ Сибирский федеральный университет \\ Россия, 660041, Красноярск, пр. Свободный, 79
}

В статье представлена новая стратегия переработки лигниноиеллюлозного сырья соломы зерновых культур, связанная с организацией биотехнологического производства, использующего углеводы для производства биоэтанола, а также побочного производства, получающего из лигнифичированных отходов высококалорийное твердое топливо. Приведены результаты теоретических и экспериментальных исследований по сжиганию высоколигнифицированного дисперсного топлива. Предложены новые технологические решения по созданию высокоэффективных и экологически безопасных энергетических установок средней мощности, осуществляющих как энергообеспечение биотехнологического предприятия по переработке углеводов в биоэтанол, так и в случае излишков энергии энергообеспечение сопутствующих потребителей.

Ключевые слова: биомасса, биотопливо, механоактивация, микропомол, моделирование прочессов горения.

\section{Введение}

Солома зерновых культур представляет собой комплексный лигноцеллюлозный материал [1]. Целлюлозная составляющая может быть использована в биотехнологической и химической промышленности [2]. Лигниновая же составляющая является перспективным видом возобновляемых энергетических ресурсов с высокой калорийностью [3].

В России годовое производство соломы как побочного продукта растениеводства характеризуется значительными ежегодными объемами. Так, по данным Минсельхоза РФ, валовой сбор зерновых и зернобобовых культур в России в 2012 г. составил 70,7 млн т. Из указанного объема 68,5 млн т составили зерновые культуры, в том числе пшеница (37,7 млн т), ячмень $(13,9$ млн т), кукуруза ( 8,0 млн т) и рожь $(2,1$ млн т). Также в минувшем году в России было собрано 4,0 млн т овса; 1,1 млн т риса; 0,8 млн т гречихи и 0,3 млн т проса. В зерновом производстве на каждый центнер пшеницы или ржи образуется в среднем 1,2 ц соломы, для ряда сортов - до 3,0 ц [4]. Таким образом, приблизительная годовая величина только соломы зерновых (пшеницы, ржи, ячменя) в России по 2012 г. может быть оценена на уровне не менее 64 млн. т. Существующие значительные объемы возобновляемого ресурса - соломы зерновых - требуют проработанных научно-технических предложений для их использования, в том числе в качестве биотоплива. 
В настоящее время использование соломы проводится в основном в необработанном виде для различных сельскохозяйственных нужд: на удобрение, в строительстве, на корм и подстилку скоту. Как возобновляемый источник энергии данный вид сырья используется исключительно редко. Установки, сжигающие солому, существуют. Стоимость установленной тепловой мощности на подобном оборудовании около $200 \$ / \kappa В$ [5]. Однако сжигание соломы в необработанном виде из-за калорийности, нестабильности состава и теплотворной способности, затрудненного контроля скорости горения не представляется перспективным; калорийность соломы составляет лишь 17-18 МДж/кг [6].

\section{Новая стратегия комплексного использования соломы зерновых культур}

В настоящее время происходит «промышленный бум» в части совершенствования технологии и процессов переработки лигниноцеллюлозного сырья. Существуют мировые тенденции эффективного использования лигноцеллюлозы. Так, на биотехнологических предприятиях, осуществляющих выпуск биоэтанола из целлюлозной составляющей, предлагается использование побочных лигниновых отходов в качестве твердого топлива. Таким образом, солома зерновых культур может рассматриваться как источник получения двух ценных товарных продуктов - углеводов (прежде всего целлюлозы) для пищевой, биотехнологической, химической промышленности и лигнина для энергетических нужд. Такое комплексное использование растительной биомассы позволит повысить его эффективность [7, 8].

Опыта строительства заводов в России по биотехнологической переработке соломы на данный момент не существует. По аналогии с США (табл. 1), для условий России можно оценить рыночный потенциал биотехнологических производств. Если предположить, что заводы с потребностью 1000 т соломы в сутки при низких ценах на этанол не эффективны, то при вы-

Таблица 1. Экономически целесообразное число заводов по переработке соломы для различных регионов США [9]

Table 1. Economically viable number of straw processing plants for different regions of the United States [9]

\begin{tabular}{|c|c|c|c|c|c|c|}
\hline \multirow[t]{2}{*}{ Регион } & \multicolumn{2}{|c|}{$\begin{array}{c}\text { Цена этанола } \\
1,15 \text { долл. США/галлон }\end{array}$} & \multicolumn{2}{|c|}{$\begin{array}{c}\text { Цена этанола 1,25 долл. } \\
\text { США/галлон }\end{array}$} & \multicolumn{2}{|c|}{$\begin{array}{c}\text { Цена этанола 1,35 долл. } \\
\text { США/галлон }\end{array}$} \\
\hline & $1000 \mathrm{~T} / \mathrm{cyт}$ & 2000 т/сут & 1000 т/сут & 2000 т/сут & 1000 т/сут & 2000 т/сут \\
\hline Айова & 0 & 13 & 1 & 16 & 27 & 18 \\
\hline Иллинойс & 0 & 11 & 0 & 13 & 23 & 15 \\
\hline Индиана & 0 & 4 & 0 & 6 & 10 & 7 \\
\hline Канзас & 0 & 0 & 0 & 0 & 2 & 1 \\
\hline Миннесота & 0 & 7 & 0 & 10 & 17 & 10 \\
\hline Миссури & 0 & 0 & 0 & 0 & 2 & 2 \\
\hline Небраска & 0 & 9 & 3 & 10 & 18 & 11 \\
\hline Огайо & 0 & 1 & 0 & 3 & 4 & 3 \\
\hline Ю. Дакота & 0 & 1 & 0 & 1 & 1 & 1 \\
\hline Висконсин & 0 & 1 & 0 & 3 & 4 & 4 \\
\hline Всего & 0 & 47 & 4 & 62 & 108 & 72 \\
\hline
\end{tabular}


соких ценах число заводов может быть на уровне тридцати предприятий. Количество заводов с потребностью 2000 т соломы в сутки - 15-20 в зависимости от цен на этанол.

В Институте химии твердого тела и механохимии СО РАН получены экспериментальные образцы порошкового топлива из растительного сырья с различной степенью дисперсности (50-140 мкм) и различным содержанием лигнина (18-60 \%) с применением биотехнологической обработки ферментами и механической активации в центробежно-роликовой и струйной мельнице [10].

Технология включает стадию заготовки и сушки сырья, предварительное измельчение до фракции менее 2 мм и последующую механическую активацию в энергонапряженных аппаратах. Разработанная технология проста в реализации и может быть масштабирована до полупромышленных и промышленных масштабов с использованием отечественного оборудования, представленного на рынке. Полученные образцы были испытаны в горелке (разработка ИТ СО PAН) и признаны перспективными для использования в экологически чистых энергоустановках.

\section{Повышение эффективности сжигания лигниновой составляющей соломы зерновых культур за счет ее механохимической обработки}

Эффективность сжигания (выход на автотермический режим горения, полнота сжигания углерода, снижение окислов азота) лигниновой составляющей соломы зерновых культур, как и любого другого твердого топлива, определяется его химической активностью. В Институте теплофизики СО РАН ведутся исследования по повышению химической активности твердого топлива $[11,12]$, в том числе полученного из соломы зерновых культур. Для угольного топлива ранее было продемонстрировано увеличение химической активности при микропомоле в специальных мельницах ударного типа - дезинтеграторах, молотковых мельницах [13].

Оптимальным способом использования тонкодисперсного топлива является сжигание в факеле. Для исследования процессов сжигания и энергетического использования механически активированных твердых топлив в ИТ СО РАН разработаны испытательные стенды производительностью по топливу до 2,5 т/ч и мощностью до 5 МВт, совмещенные с системами подготовки топлива и улавливания продуктов горения [14].

Проведение механохимической обработки приводит к тому, что топливо улучшает свои теплотехнические свойства. При горении факел топлива по своим размерам, теплонапряженности и интенсивности выгорания приближается к газовому или мазутному. Это позволяет производить высокоэффективное замещение дорогих высокореакционных топлив, таких как газомазутное топливо, а также использовать газомазутное оборудование (котлы) для сжигания тонкодисперсного твердого топлива.

Топочный процесс при сжигании растительного сырья является сложным для исследования, проводимого с последовательным использованием таких методов:

- математического моделирования топочного процесса;

- физического моделирования на лабораторной установке мощностью 50-100 кВт;

- физического моделирования на экспериментальном тепловом стенде мощностью 5 MВТ для проведения полномасштабных экспериментов. 
Значительную трудность при разработке математической модели горения биомассы составляет больший разброс в химических и физических свойствах данного вещества по сравнению с каменным углем. Ранее отработанные математические модели для процесса термической переработки угля [15] адаптировались для моделирования процессов горения биомассы. Математическая модель основана на уравнениях Рейнольдса с учетом межфазного взаимодействия. Для описания процессов движения частицы используется метод Лагранжа. Движение частицы описывается уравнениями динамики материальной точки с учетом силы сопротивления и силы тяжести. Учет турбулентности потока при движении частицы производится введением случайных флуктуаций скорости газа в уравнение движения для частиц. Решение уравнения переноса лучистой энергии базируется на Р1 аппроксимации метода сферических гармоник для серой двухфазной двухтемпературной среды. Процесс горения угольной частицы рассматривается в виде последовательных этапов: испарение влаги из топлива, выход и горение летучих компонент и горение коксового остатка. Для расчета скорости выхода летучих веществ была выбрана одностадийная модель. Как показали расчетные исследования [16], при правильном выборе эффективных кинетических констант скорости выхода летучих веществ из частицы органического топлива данная модель обеспечивает достаточную для инженерных задач точность. Для учета особенности горения частицы биотоплива в модель движения частиц был введен корректирующий фактор, учитывающий несферическую форму частицы, а также использованы кинетические характеристики процесса выхода летучих веществ и горения углеродного (коксового) остатка, характерные для биомассы.

Физическое моделирование на лабораторной установке мощностью 50-100 кВт позволило исследовать аэродинамику горения, так как аэродинамика камеры сгорания оказывает решающее влияние на топочный процесс и определяет оптимальные режимы воспламенения топлива. Исследованное горелочное устройство производило устойчивый факел при варьировании в широких пределах геометрических граничных условий вне зависимости от способа подачи топлива и стехиометрического соотношения топливо-воздух, вплоть до ультраобедненных смесей.

Физическое моделирование на экспериментальном стенде мощностью до 5 МВт предназначалось для рассмотрения процессов горения, приближенных к натурным испытаниям. Созданы системы приготовления и подачи топлива, горелочное устройство на производительность 2,5 т/ч соломы.

Одной из серьезных проблем технологии сжигания растительного мелкодисперсного топлива являются надежно работающие питатели, используемые для угольного топлива. Растительные материалы имеют низкую насыпную плотность, что не позволяет создать устойчивую подачу сырья из бункера-накопителя. Для подачи сырья в измельчитель (молотковую мельницу или дезинтегратор) предложен питатель шнекового типа с регулированием подачи за счет изменения частоты вращения оси.

Основным устройством для механохимической обработки топлива, позволяющим приблизить его к высокореакционным газомазутным топливам, признаны мельница со свободным типом удара - дезинтегратор. Использованы дезинтеграторы, разрабатываемые фирмой «Продсельмаш» в г. Новосибирске с производительностью от 150 до 2500 кг/ч. Для них обо-

$$
-233-
$$


снованы оптимальные расходы транспортного воздуха, дающие возможность получать требуемую тонину помола.

Пневмотранспортом с эжекторной подачей первичного воздуха мелкодисперсное топливо после дезинтегратора подавалось в форкамеру вихревой горелки, затем в предтопок. На рис. 1 указаны места измерения температуры и газа по тракту процесса горения. Поджиг топлива осуществлялся в вихревой форкамере штатным запально-защитным устройством (33У) с использованием пропан-бутановой смеси. После 300-400 с 33У отключается, так как процесс выходит на автотермический режим горения с температурой до $1200{ }^{\circ} \mathrm{C}$ (топливо с $18 \%$ лигнина) и $1300{ }^{\circ} \mathrm{C}$ (топливо с 30 \% лигнина и более). После предтопка в камере дожигания вторичного дутья идет процесс доокисления уходящих газов.

Определяющей характеристикой эффективного сжигания любого топлива является оптимальный расход воздуха. В проводимых исследованиях контроль, регулирование и поддержание расходов первичного и вторичного воздуха для сжигания топлива осуществлялись после включения дымососа, питателя топлива, дезинтегратора, вентиляторов первичного и вторичного дутья. Измерение расходов вторичного воздуха осуществляется трубкой Прандтля, установленной на срезе патрубка стандартного вентилятора. Первичный воздух формировался в единую систему последовательным включением четырех вентиляторов с расходом 125 м $3 / 4$ каждый. Контроль и измерение первичного воздуха осуществлялся на срезе входного патрубка расходомером. Расход первичного и вторичного воздуха можно было регулировать с помощью шибера. Для эффективной эвакуации частиц пыли из дезинтегратора по тракту подачи топлива в форкамеру установлен эжектор. Последовательное включение вентиляторов позволяло дополнительно с шибером регулировать необходимое количество первичного воздуха.

Температуры и состав отходящих газов измеряли по длине и сечению тракта горения топлива (рис. 1) в реальном масштабе времени с выводом информации на ЭВМ. В предтопке измерения осуществлялись платино-платинородиевыми термопарами, а в зоне дожигания, после вторичного дутья, хромель-алюминиевыми термопарами. Газовый состав продуктов горения измерялся многокомпонентным $\left(\mathrm{CO}, \mathrm{CO}_{2}, \mathrm{O}_{2}, \mathrm{SO}_{2}, \mathrm{NO}_{x}\right)$ газоанализатором разработки ИТ СО

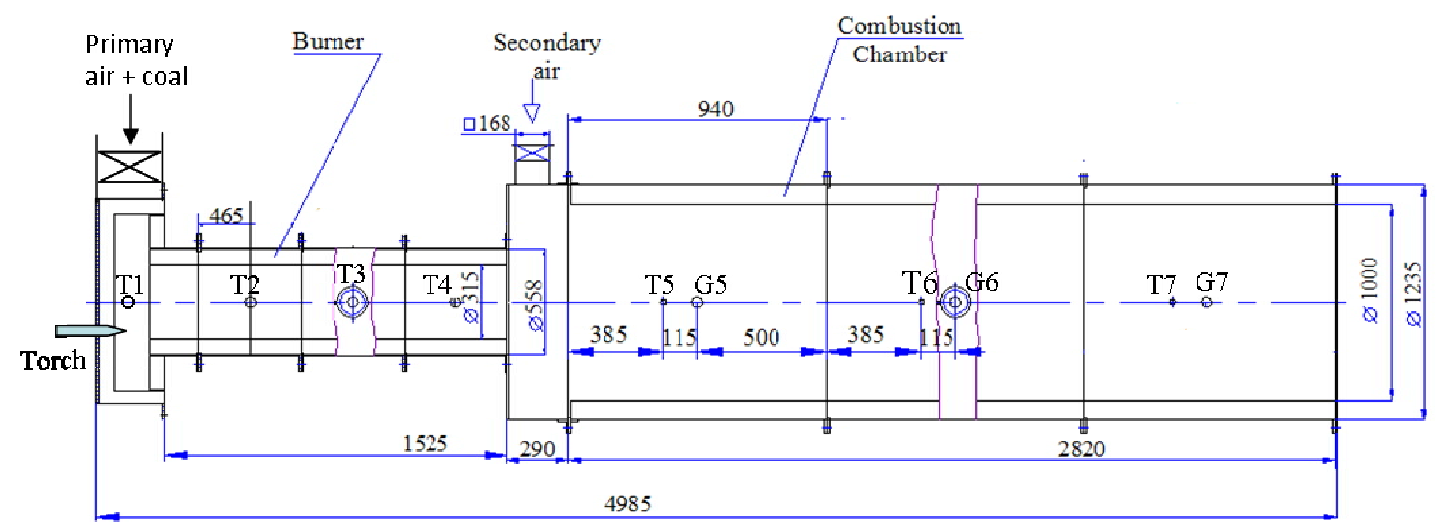

Рис. 1. Схема теплового стенда мощностью до 5 МВт [13]

Fig. 1. Scheme of a thermal stand up to $5 \mathrm{MW}$ [13] 
РАН с погрешностью не выше 5 \%. В процессе измерений шел постоянный контроль отсутствия зольных и сажевых отложений на термопарах и системах отбора газа.

В результате проведенных исследований [17] по воспламенению и горению механически обработанного лигнинсодержащего топлива из соломы пшеницы установлены оптимальные технологические параметры: 25-30 \% избыток первичного воздуха по отношению к теоретическому для полного горения, соотношение между первичным и вторичным воздухом равняется 1.2 - 1.4. Выявлены оптимальные параметры соотношения исследуемых топлив и окислителя первой и второй ступеней горелки с соблюдением нормативных экологических характеристик сжигания. Эксперименты выявили устойчивое автотермическое горение продуктов переработки растительного сырья с содержанием лигнина 18-60 \% при температуре факела $1200-1300{ }^{\circ} \mathrm{C}$ в горелочном устройстве.

Проведенные численные исследования процесса горения лигнинсодержащего топлива на 5 МВТ стенде ИТ СО РАН были направлены на оптимизацию режимов горения и конструкции горелочно-топочного устройства для сжигания различных биотоплив. Данные исследования показали, что измельчение лигнинсодержащего топлива из соломы пшеницы в дезинтеграторе по сравнению с измельчением в центробежно-роликовой мельнице при прочих равных условиях позволяет добиться более эффективного воспламенения топлива. Так, на рис. 2 показаны температурные поля при сжигании лигнинсодержащего топлива, предварительно измельченного на разных мельницах. Можно видеть, что измельчение в дезинтеграторе при равных расходах топлива и окислителя обеспечивает более высокие температуры на выходе из первой ступени горелки.

Исследованное горелочное устройство позволяет реализовать устойчивый факел при варьировании в широких пределах геометрических граничных условий вне зависимости от способа подачи топлива и стехиометрического соотношения топливо-воздух, вплоть до ультраобедненных смесей, что дает, в частности, возможность контроля образования окислов азота. Например, измерения температуры для обедненной смеси с $\varphi=0.5$ показали, что максимальные температуры в зоне реакции не превышают $1350{ }^{\circ} \mathrm{C}$, что гарантирует предельно низкий уровень образования оксидов $\mathrm{NO}_{x}$. Данный вывод подтвердили проведенные измерения выбросов, которые показали, что концентрация $\mathrm{NO}_{x}$ в продуктах сгорания в данном горелочном устройстве может поддерживаться на уровне, не превышающем значения 10 ppm. При этом снижение
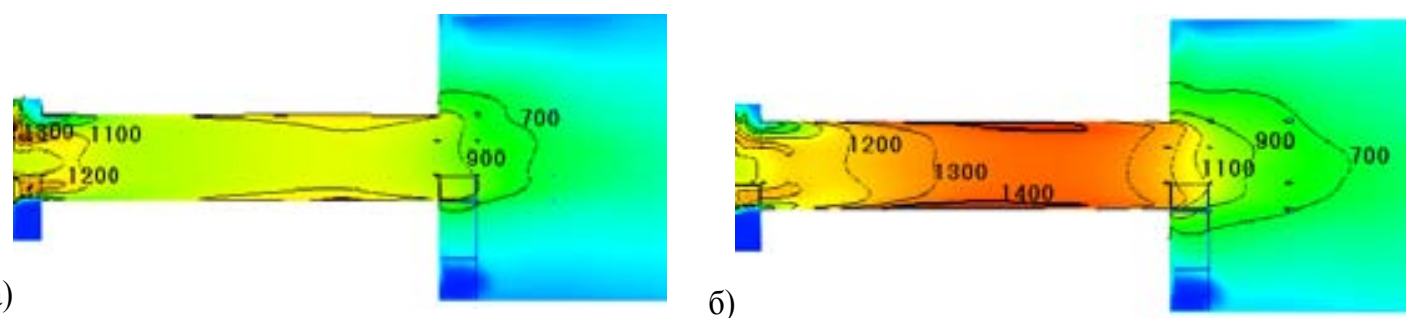

Рис. 2 Распределение температур в центральном сечении огневого стенда: а - при измельчении топлива в центробежно-роликовой мельнице; б - при измельчении топлива в мельнице-дезинтеграторе

Fig. 2. Distribution of temperatures in the center section of the fire stand. $a-$ When grinded fuel in a centrifugalroller mill; $\sigma$ - When grinded fuel in a mill-disintegrator 
образования $\mathrm{NO}_{x}$ достигается в условиях полного выгорания топлива, о чем свидетельствует близкая к нулю концентрация СО в продуктах сгорания.

Данные по скоростям позволяют сделать вывод о том, что разработанное горелочное устройство с тангенциальным завихрителем позволяет формировать закрученную горелочную струю с центральным провалом на профилях осевой скорости. Такая аэродинамическая структура течения может считаться оптимальной, поскольку центральная область замедленного течения создает условия для эффективной стабилизации пламени. Важен тот факт, что в условиях горения за счет заполнения центральной рециркуляционной зоны горячими продуктами горения, выполняющими функцию поджига свежей топливно-воздушной смеси, существенно подавляется сильная нестационарность течения в форме прецессирующего вихревого ядра, которая часто реализуется в горелочных системах с закруткой. Горелочное устройство производит достаточно компактный факел, состоящий из нижней ламинизированной части в виде перевернутого конуса с точкой присоединения, устойчиво зафиксированной на нижнем торце камеры, и верхней турбулизированной части, характеризующейся интенсивным смешением и горением. Нижняя часть выполняет роль стабилизатора факела, а верхняя - зоны с интенсивным смешением, где происходит выгорание основной части топлива.

Принципиальным результатом экспериментальных исследований явилось то, что длина пылелигнинового факела позволяет использовать камеры сгорания, близкие по параметрам к газомазутным. На этом основании в качестве основных типов котлов для сжигания тонкодисперсного растительного сырья рекомендованы котлы с применением факельного сжигания. При этом могут быть использованы газомазутные котлы, серийно выпускаемые в России, с производительностью от 6 т пара/ч и выше, дооснащенные системами топливоприготовления, горелочными устройствами и пылеулавливания для энергетического использования.

\section{Технико-экономическая оценка научно-технического предложения по использованию соломы зерновых культур для энергетических нужд в реальном секторе экономики}

В качестве современного предложения по использованию соломы зерновых культур для энергетических нужд в реальном секторе экономики к рассмотрению принимался совместный проект ИХТТМ СО РАН (г. Новосибирск) и НПО «Химавтоматика» (г. Москва) по биотехнологической переработке в биоэтанол до 30 тыс. т соломы в год. Для переработки такого количества соломы, по данным разработчика, необходима суммарная тепловая и электрическая мощность 1,4 МВт. В рассматриваемом проекте при биотехнологической переработке используется только углеводная составляющая соломы, а отработанный остаток, содержащий лигнин (горючий остаток), рассматривается как отход производства, подлежит утилизации или может быть использован в качестве топлива. Оценочное количество отходов переработки соломы по указанной технологии равно 24000 т/год или 4 т/ч.

Приведенные выше базовые данные проекта биотехнологического предприятия применены при разработке научно-технического предложения по использованию соломы зерновых культур для энергетических нужд в реальном секторе экономики.

В формируемом научно-техническом предложении по использованию соломы зерновых культур для энергетических нужд принимался внешний источник электрической энергии, а 
обеспечение тепловой энергией рассматривалось от собственного источника - котельной на лигнифицированном побочном продукте, получаемом в основной биотехнологической операции.

Для экономической оценки была осуществлена привязка биотехнологического предприятия к конкретному региону - Новосибирской области, Ордынскому району. Регион рассматривался как потенциальный поставщик соломы и потребитель тепловой энергии от котельной в случае ее излишков для биотехнологического предприятия. Стоимостные показатели привязаны к условиям рассматриваемого региона в 2012 г.

Результаты исследования процесса сжигания мелкодисперсного лигнифицированного топлива показали, что длина пылевого факела вполне вписывается в габаритные размеры топок газомазутных котлов. Поскольку котельными заводами России (БиКЗ и др.) серийно выпускается типоряд газомазутных котлов на широкий диапазон паропроизводительности и параметров пара, то представляется целесообразным их применение для энергетического использования при сжигании отходов переработки соломы зерновых культур на биотехнологическом предприятии при дооснащении системами топливоприготовления, горелочными устройствами и пылеулавливания. Кроме того, положительно следующее: относительно более низкая стоимость газомазутных котлов, простота конструкции, отсутствие мощного фундамента и другие преимущества. Таким образом, газомазутные котлы обладают несомненными преимуществами и предпочтительны при сжигании пылевидного лигниносодержащего растительного сырья, в частности соломы злаковых культур.

Для сжигания 24000 т/год лигниносодержащего топлива с теплотворной способностью 1700-2000 ккал/кг с 6000 ч работы энергетической установки в год рассматривалось предложение - строительство собственной котельной с установкой в ней серийного газомазутного котла типа ДЕ-10-14- ГМ производительностью 10 т пара / час (6 МВт), переоборудованного для сжигания твердого дисперсного лигнинсодержащего топлива.

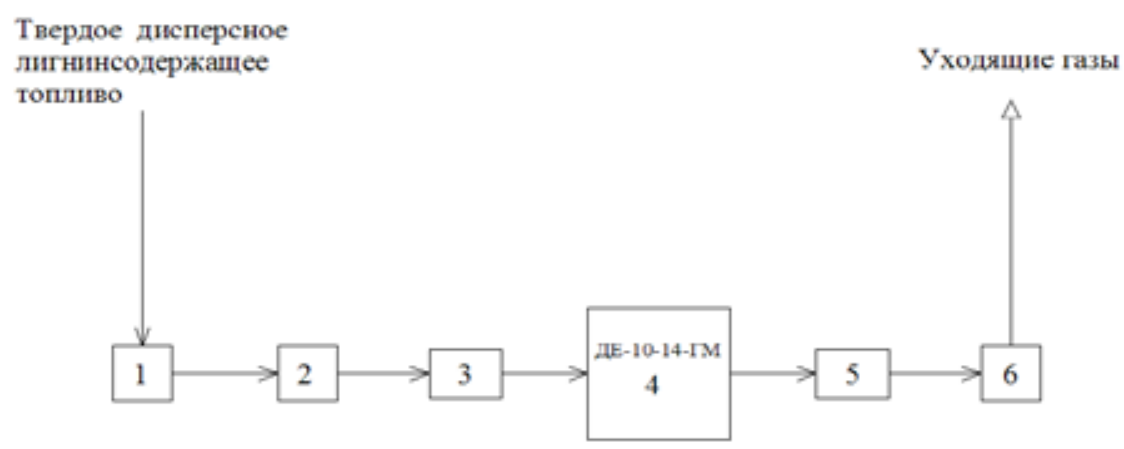

Рис. 3. Схема котельной на твердом мелкодисперсном лигнинсодержащем топливе: 1 - шнековый питатель, 2 - дезинтегратор, 3 - вихревая горелка, 4 - газомазутный котел ДЕ-10-14-ГМ, 5 - система пылеулавливания, 6 - дымосос

Fig. 3. Diagram of a boiler house on solid fine-dispersed lignin-containing fuel: 1 - screw feeder, 2 - disintegrator, 3 - vortex burner, 4 - gas-oil boiler DE-10-14-GM, 5 - dust collection system, 6 - smoke exhaust 
Таблица 2. Оценка стоимости оборудования основных узлов котельной

Table 2. Estimation of the cost of equipment of the main boiler house units

\begin{tabular}{|c|c|c|c|}
\hline № & Наименование оборудования & $\begin{array}{c}\text { Стоимость }, \\
\text { млн руб. }\end{array}$ & Производитель \\
\hline 1 & Шнековый питатель с дозатором & 0,3 & ООО «Продсельмаш» \\
\hline 2 & Дезинтегратор ДЗМ-2,5 & 2,0 & ООО «Продсельмаш» \\
\hline 3 & Вихревая горелка & 0,8 & ОАО «СибКОТЭС» \\
\hline 4 & Газомазутный котел ДЕ-10-14 ГМ & 7,9 & Бийский котельный завод \\
\hline 5 & Система пылеулавливания & 0,5 & ОАО «СибКОТЭС» \\
\hline 6 & Дымосос & 0,3 & Бийский котельный завод \\
\hline 7 & Транспортные затраты & до 1,5 & Экспертная оценка \\
\hline 8 & Прочие затраты & до 2,0 & Экспертная оценка \\
\hline Итого & & 15,3 & \\
\hline
\end{tabular}

Таблица 3. Капитальные затраты на сооружение котельной

Table 3. Capital costs for the construction of a boiler house

\begin{tabular}{|c|c|c|}
\hline № & Наименование затрат & $\begin{array}{c}\text { Стоимость, млн } \\
\text { руб. }\end{array}$ \\
\hline 1 & Здание котельной & 4,0 \\
\hline 2 & Подготовка, установка оборудования, запуск котельной & 1,5 \\
\hline 2.1 & Проектно-изыскательские работы & 15,3 \\
\hline 2.2 & Оборудование котельной (см. табл. 2) & 4,0 \\
\hline 2.3 & Строительно-монтажные работы & 2,0 \\
\hline 2.4 & Шефмонтаж, пусконаладочные и испытательные работы & 2,0 \\
\hline 2.5 & Резерв средств на непредвиденные работы и затраты & 28,8 \\
\hline
\end{tabular}

На рис. 3 приведена схема котельной, где обозначены основные принципиальные узлы, подлежащие дальнейшей оценке, а в табл. 2 - их стоимостные оценки. В табл. 2 и 3 приведены затраты на оборудование и сооружение котельной.

Себестоимость производства тепловой энергии на мазутных котельных Новосибирской области составляет в среднем 1680 руб/Гкал. Доля топливной составляющей в ней -73 \%, доля эксплуатационных затрат (топливо, электроэнергия, вода, зарплата обслуживающего персонала, амортизация, прочие) - 27 \%. Исходя из этого, эксплуатационные затраты на выработку 1 Гкал выработанной тепловой энергии для котельной составят 453,6 руб./Гкал, а годовые эксплуатационные затраты - 16,3 млн руб. Годовой объем производства тепловой энергии на котельной при мощности 6 Гкал/ч и 6000 ч установленной мощности составляет 36 тыс. Гкал. В табл. 4 приведены сводные данные по затратам на осуществление предлагаемой технологии, а также другая информация, необходимая для экономической оценки. 
Таблица 4. Сводная информация для экономической оценки предложения «Строительство котельной на твердом дисперсном лигнинсодержащем топливе»

Table 4. Summary information for the economic evaluation of the proposal "Construction of a boiler house on solid dispersed lignin-containing fuel"

\begin{tabular}{|l|c|}
\hline \multicolumn{1}{|c|}{ Исходные параметры } & Показатель \\
\hline Биотехнологическое предприятие & 0,6 \\
\hline Тепловая мощность биотехнологического предприятия, Гкал/ч & 6000 \\
\hline Число часов использования тепловой энергии в год, час & 3,6 \\
\hline Потребность в теплоэнергии биотехнологического предприятия, Гкал/год & 6,0 \\
\hline Котельная & 6000 \\
\hline Тепловая мощность котла, Гкал/ч & 36000 \\
\hline Число часов использования тепловой энергии в год, час & 15300 \\
\hline Выработка тепловой энергии Qкот, тыс. Гкал/год & 13500 \\
\hline Стоимость оборудования для котельной К об, тыс. руб. & 28800 \\
\hline Стоимость строительства котельной К кот. тыс. руб. & 16330 \\
\hline Дополнительные капитальные затраты на предложение К доп & \\
\hline Эксплуатационные годовые затраты предложения Э экп, тыс. руб. & 32400 \\
\hline Дополнительные доходы для биотехнологического предприятия & 1332 \\
\hline Объем возможной продажи тепловой энергии на сторону Q прод Гкал/год & 43200 \\
\hline Цена продаваемой теплоэнергии, руб./Гкал & 1,1 \\
\hline Годовой доход от продажи энергии, Э прод,тыс. руб. & \\
\hline Срок окупаемости предложения, лет, Т ср.куп & \\
\hline
\end{tabular}

Как видно, вырабатываемая тепловая энергия существенно больше потребности предприятия и поэтому у биотехнологического предприятия появляется возможность продавать излишки тепловой энергии сторонним потребителям, что составит для предприятия дополнительные доходы. Срок окупаемости проекта рассчитывается как отношение необходимых дополнительных затрат к разнице затрат от продажи и эксплуатационных затрат. Как видим, рассматриваемый проект является экономически эффективным и окупается за 1,1 года.

\section{Выводы}

1. Растительное сырье - солома злаковых - может рассматриваться как источник основного продукта - целлюлозы для биотехнологической и химической промышленности (выработка этанола) и лигнифицированного остатка (высококалорийного топлива).

2. Экспериментальными исследованиями на стенде мощностью 5 МВт показано:

- возможно обеспечение устойчивого автотермического горения продуктов переработки растительного сырья с содержанием лигнина 18-60 \% при приемлемых значениях температур факела в горелочном устройстве и продуктов их сжигания;

- длина топливного факела позволяет использовать камеры сгорания, близкие по параметрам к газомазутным, что является основанием использовать для сжигания лигниносодержащей соломы злаковых существующее газомазутное котельное оборудование. 
3. Экономическая эффективность биотехнологических предприятий по переработке соломы с механохимической обработкой лигниноцеллюлозного сырья может быть повышена за счет использования отходов производства для выработки тепловой энергии, используемой как для самого биотехнологического предприятия, так и в случае излишков для сопутствующих потребителей.

4. Для биотехнологического предприятия, перерабатывающего 30000 т соломы в год, сформулировано предложение «Строительство котельной на твердом дисперсном лигнинсодержащем топливе» с установкой газомазутного котла ДЕ-10-14ГМ. Проведенная оценка эффективности проекта показала, что срок окупаемости составляет 1,1 года.

Численные исследования горения топлива выполнены при поддержке РФФИ (грант № 15-38-20969).

\section{Список литературы}

[1] Raven P.H., Evert R.F., Eichhorn S.E. Biology of Plants. New York, Worth Publishers, 1986. $775 \mathrm{p}$.

[2] Domínguez-Bocanegra A.R., Torres-Muñoz J.A., López R.A. Production of Bioethanol from agro-industrial wastes, Fuel, 2015, 149, 85-89.

[3] Berghel J., Frodeson S., Granström K., Renström R., Ståhl M., Nordgren D., Tomani P. The effects of kraft lignin additives on wood fuel pellet quality, energy use and shelf life, Fuel Processing Technology, 2013, 112, 64-69.

[4] Нормативы и методика применения побочной продукции сельскохозяйственных культур для обеспечения бездефицитного баланса органического вещества в почвах на землях сельскохозяйственного назначения. Изд-во п. Рассвет, 2010. 50 с. [Norms and methods of using by-products of agricultural crops to ensure a deficit balance of organic matter in soils on agricultural land. Izd-vo p. Rassvet, 2010, 50 p. (in Russian)]

[5] Красуцкий Е.В., Фурсов И.Д., Жуков Е.Б., Якимова И.С., Пузырев Е.М. Исследование сжигания сельскохозяйственных отходов. Ползуновский вестник, 2012, 3(1), 47-50. [Krasutsky E.V., Fursov I.D., Zhukov E.B., Yakimova I.S., Puzyrev E.M. Study of burning agricultural waste. Polzunovsky vestnik, 2012, 3 (1), 47-50 (in Russian)]

[6] Бычков А.Л., Денькин А.И., Тихова В.Д., Ломовский О.И. Расчет теплоты сгорания лигноцеллюлозы на основании данных элементного анализа. Химия растительного сырья, 2014, 3 , 99-104. [Bychkov A.L., Denkin A.I., Tikhova V.D., Lomovsky O.I. Calculation of the calorific value of lignocellulose on the basis of elemental analysis data. Chemistry of plant raw materials, 2014, 3, 99-104 (in Russian)]

[7] Lomovsky O., Bychkov A., Lomovsky I., Logvinenko V., Burdukov A. Mechanochemical production of lignin-containing powder fuels from biotechnology industry waste: A review, Thermal Science, 2015, 19(1), 219-229.

[8] Pickard S.C., Daood S.S., Pourkashanian M., Nimmo W. Co-firing coal with biomass in oxygen- and carbon dioxide-enriched atmospheres for CCS applications, Fuel, 2014, 137, 185-192.

[9] Haykiri-Acma H. The role of particle size in the non-isothermal pyrolysis of hazelnut shell, Journal of Analytical and Applied Pyrolysis, 2006, 75, 211-216. 
[10] Bychkov A.L., Buchtoyarov V.A., Lomovsky O.I. Mechanical pretreatment of corn straw in a centrifugal roller mill, Cellulose Chemistry and Technology, 2014, 48 (5), 545-551.

[11] Бурдуков А.П., Попов В.А., Чернецкий М.Ю., Дектерев А.А., Ломовский О.И., Бычков А.Л. Использование мелкодисперсного лигноцеллюлозного сырья в качестве твердого топлива. Ползуновский вестник, 2013, 3(2), 16-27. [Burdukov A.P., Popov V.A., Chernetsky M.Yu., Dekterev A.A., Lomovsky O.I., Bychkov A.L. Use of fine-dispersed lignocellulosic raw materials as solid fuel. Polzunovsky vestnik, 2013, 3(2), 16-27 (in Russian)]

[12] Чернецкий М.Ю., Дектерев А.А., Бурдуков А.П. Расчетное исследование факельного горения мелкодисперсного лигноцеллюлозного сырья. Журнал СФУ. Техника и технологии, 2013, 6(6), 625-636 [Chernetskiy M.Yu., Dekterev A.A., Burdukov A.P. Numerical Research of Pulverized Combustion of Micro-Grinded Lignocellulose Raw Materials, J. Sib. Fed. Univ. Eng. technol., 2013, 6(6), 625-636 (in Russian)]

[13] Burdukov A.P., Popov V.I., Hanjalić K., Chernetskiy M.Y., Dekterev A.A. Mechanical activation of micronized coal: prospects for new combustion applications, Applied Thermal Engineering, 2014, $74,174-181$.

[14] Бурдуков А.П., Чернецкий М.Ю., Дектерев А.А., Ануфриев И.С., Стрижак П.А., Гребеньков П.Ю. Исследование процессов воспламенения, горения и образования вредных веществ при сжигании твердого органического топлива на стенде с вихревой камерой. Теплоэнергетика, 2016, 1, 64-69. [Burdukov A.P., Chernetskii M.Yu., Dekterev A.A., Anufriev I.S., Strizhak P.A., Greben'kov P.Yu. Study of Ignition, Combustion, and Production of Harmful Substances upon Burning Solid Organic Fuel at a Test Bench with a Vortex Chamber. Thermal Engineering, 2016, 63(1), 64-69 (in Russian)]

[15] Майданик М.Н., Вербовецкий Э.Х., Дектерев А.А., Чернецкий М.Ю., Гаврилов А.А., Бойков Д.В., Бердин С.В. Математическое моделирование топки и поворотного газохода котла П-50Р при совместном сжигании твердого и газообразного топлива. Теплоэнергетика, 2011, 6, 37-42. [Maidanik M.N., Verbovetskii E.Kh., Dekterev A.A., Chernetskii M.Yu., Gavrilov A.A., Boikov D.V., Berdin S.V. Mathematical simulation of the furnace and turning gas conduit of a P-50R boiler during joint combustion of solid and gaseous fuel. Thermal Engineering (English translation of Teploenergetika), 2011, 58(6), 37-42 (in Russian)]

[16] Chernetskaya N.S., Chernetskiy M.Yu., Dekterev A.A. Numerical investigation of influence thermal preparation coal on nitric oxides formation in combustion process. Журнал СФУ. Техника и технологии, 2014, 7(1), 83-95. [Chernetskaya N.S., Chernetskiy M.Yu., Dekterev A.A. Numerical investigation of influence thermal preparation coal on nitric oxides formation in combustion process. Sib. Fed. Univ. Eng. technol. 2014, 7(1), 83-95 (in Russian)]

[17] Кузнецов В.А., Дектерев А.А., Сентябов А.В., Чернецкий М.Ю. Расчетное исследование влияния моделей выхода летучих веществ на процессы горения пылеугольного топлива при закрутке потока. Журнал СФУ. Техника и технологии, 2016, 9(1), 15-23 [Kuznetsov V.A., Dekterev A.A., Sentyabov A.V., Chernetskiy M.Y. Numerical Study of Devolatilization Models on the Combustion Process of Pulverized Fuel Flow Swirling, J. Sib. Fed. Univ. Eng. technol., 2016, 9(1), $15-$ 23 (in Russian)] 